\title{
Economic Analysis of Charitable Donations
}

\author{
Moon Young Kang \\ KAIST College of Business, Seoul, Korea \\ mkang@business.kaist.ac.kr \\ Byungho Park \\ KAIST College of Business, Seoul, Korea \\ mediapark@business.kaist.ac.kr \\ Sanghak Lee \\ University of lowa, lowa City, lowa, USA \\ sanghak-lee@uiowa.edu \\ Jaehwan Kim ${ }^{1}$ \\ Korea University Business School, Seoul, Korea \\ jbayes@korea.ac.kr \\ Greg Allenby \\ Ohio State University, Columbus, Ohio, USA \\ allenby.1@osu.edu
}

Received: 5 March 2016 / Revised: 17 June / 2016 / Accepted: 8 August 2016 / Published online: 6 October 2016

\begin{abstract}
This paper examines the effect of message characteristics on donation behavior using an economic model of giving. The utility of giving can come from one's own contribution and possibly from the combined contributions of others. Donors are assumed to be constrained utility maximizers, and the message attributes affect the degree to which they react altruistically or egoistically. The model is estimated with data from an incentive-aligned study of South Korean consumers, and implications for message optimization and donor targeting are explored.
\end{abstract}

JEL classification: C110, D640, C510, M300

Keywords: direct utility model, hierarchical Bayes, altruism, non-profit marketing

\section{INTRODUCTION}

The desire to help others is a naturally occurring trait of human behavior. Helping others and doing good is revealed when we make charitable donations, volunteer for community service and assist the elderly. Helping behaviors are important to non-profit organizations operating for the benefit of public welfare, education, health care, disaster relief and other social services.

1 Corresponding author. Jaehwan Kim, Professor of Marketing, Korea University Business School, 5 Anam, Seongbuk-gu, Seoul 136-701, Korea Phone: (82)232902603, Fax: (82)29227220, e-mail: jbayes@korea.ac.kr 
Voluntary donations in the form of money, time and expertise are essential resources that allow charitable organizations to achieve their goals and mission.

The factors affecting giving behavior have been extensively studied in marketing, psychology and economics where the concept of altruistic, or selfless, motivation is contrasted with egoistic motives for giving (Becker, 1974; Bendapudi et al., 1996). This characterization of the motivation for giving is often described as a trait-like aspect of one's personality (Reed et al., 2007), or assumed to be dependent on situational factors that promote empathetic identification with recipients (Small et al., 2007). In reality, it is doubtful that donors act for purely altruistic or purely egoistic reasons during any specific instance of giving. It is also doubtful that donors are consistently altruistic or egoistic in response to appeals for help. The degree to which donors identify with the recipient, for example, is dependent on aspects of the appeal. In this paper we employ a heterogeneous model of giving that represents donors as having a mixture of altruistic and egoistic motivations, referred to as "warm-glow" giving by Andreoni (1989).

Our interest is in understanding aspects of an appeal for donations that drive more altruistic versus more egoistic responses from respondents. Appeals that prompt altruistic giving are more likely to be useful early in a donation campaign when it is uncertain if a fund-raising effort will reach its goal because altruistically motivated people give selflessly, and not because others have given or because they want to be associated with a winning campaign. Appeals that prompt egoistic motives will likely be more effective later in a campaign when a large portion of the goal has already been achieved. The timing and nature of appeals for donations are important aspects of campaign management.

We employ an economic model to study the impact of communication content and timing on individuals' tendencies to act egoistically. Our model relates aspect of an appeal, such as the visual portrayal of the need, to the marginal utility of egoistic versus altruistic giving. The model is similar to the impure altruistic model (Andreoni, 1989, 1990) where donations are viewed as an economic outcome arising from an individual's decision to give or not. However, our focus is on understanding factors that influence egoistic versus altruistic giving, and using this information to maximize campaign contributions. In contrast to studies in economics that focused on aggregate giving and policy implications using cross-sectional data (DellaVigna et al., 2012), our analysis focuses on intra-individual variation in donor behavior for the purpose of optimizing appeals at the individual level.

We conducted an incentive-aligned experiment (Ding et al., 2005) where donors are exposed to multiple appeals. Our model allows for corner and interior solutions in the data, whereas the extant models allow for either interior solutions or corner solutions only. Sieg and Zhang (2012), for example, examine donation decisions, but not donation amounts, by assuming that a single decision is made each quarter of the year. We find large intra-individual variation in giving due to aspects of an appeal, and that our economic model for giving outperforms other, more descriptive models. We find that recipient-focused appeals, coupled with the absence of happiness and high arousal levels, result in the highest donation amounts, and that the value of an appeal depends on when an individual is contacted. We show that appeal customization and timing lead to a $7-8 \%$ lift in expected total donations in our data.

The rest of the paper is organized as follows. In the next section, we briefly discuss literature related to communication attributes shown to influence charitable donations. We then present our model and an empirical analysis involving experimental data. Implications of our model for communication timing are discussed, and we conclude with a discussion of issues requiring additional research. 


\section{LITERATURE REVIEW}

Research on effective advertising attributes for prompting giving behavior is briefly summarized in Table 1. Variables identified as often affecting donating behavior that we explore in our study are i) the presence or absence of the person receiving the benefit (recipient-focused); ii) whether the advertisement makes an emotional appeal (emotional); iii) the presence of appeal elements that attempt to arouse the donor (arousal); and iv) the presence of information indicating the donating behavior of others (donation by others). Each of these attributes can be embedded into an advertising campaign and used to appeal to donors.

Table 1

Selected Studies with Donation Conditions

\begin{tabular}{|c|c|c|c|c|}
\hline Studies & Recipient-Focused & Emotional Appeal & Arousal & Donations by Others \\
\hline Andreoni (1990) & & & & $\sqrt{ }$ \\
\hline Bagozzi and Moore (1994) & & $\sqrt{ }$ & & \\
\hline Brunel and Nelson (2000) & $\sqrt{ }$ & & & \\
\hline Cialdini et al. (1987) & $\sqrt{ }$ & & & \\
\hline Dickert et al. (2011) & & $\sqrt{ }$ & $\sqrt{ }$ & \\
\hline Fisher et al. (2008) & $\sqrt{ }$ & $\sqrt{ }$ & & \\
\hline Hollander (1990) & & & & $\sqrt{ }$ \\
\hline Kogut and Ritov (2005) & & $\sqrt{ }$ & $\sqrt{ }$ & \\
\hline Small and Verrochi (2009) & & $\sqrt{ }$ & & $\sqrt{ }$ \\
\hline \multicolumn{5}{|l|}{ Silverman et al (1984) } \\
\hline White and Peloza (2009) & $\sqrt{ }$ & & & \\
\hline
\end{tabular}

The effect of each factor in Table 1 has been shown to be largely significant for the donation decision. Although we elaborate more on the extant literature in the following sections, it is obvious from Table 1 that any research aimed at bringing proper policy guidelines for campaigns or communications should have these four message characteristics at the same time.

\subsection{Recipient-Focused}

There has been considerable debate in the literature on whether the motivation of donation is purely altruistic (Batson, 1990; Dovidio et al., 1990; Davis, 1994b) or partly egoistic (Piliavin et al., 1981; Batson, 1987; Batson et al., 1988; Fultz et al., 1988; Martin, 1994; Cialdini et al., 1997; White and Peloza, 2009). Advertisements for donations can focus on the benefits provided to the recipients, or alternatively to the donor himself/herself (Brunel and Nelson, 2000; Cialdini et al., 1987; Fisher et al., 2008; White and Peloza, 2009). For example, an advertisement for the Africa Food Crisis can be designed to highlight the plight of African children to promote higher levels of empathy and prosocial behavior in the form of donations (Bagozzi and Moore, 1994; Small and Verrochi, 2009). Alternatively, an advertisement could focus on the pride and happiness of the donors themselves as they identify with, and support, the mission of the organization. In this case, the motivations for charitable giving may also depend on the donors' mood (Smith et al., 1989), self-esteem (Batson, 1987) and their image conveyed to others (Arnett et al., 2003; Baumeister, 1982). While the effectiveness of any advertisement is dependent on personal aspects of donors, a substantial body of research has shown that consumers make more donations in response to a recipient-focused campaign than non-recipient-focused appeals (Goffrnan, 1959; Leary and Kowalski, 1990; White and Peloza, 2009). 


\subsection{Emotions}

Negative emotions (e.g., anger, sadness, fear, and tension) associated with the recipient of a donation have been shown to lead to sympathetic responses (Loewenstein and Small, 2007) and helping behavior in many studies (Coke et al., 1978; Bagozzi and Moore, 1994; Batson et al., 1997). Previous studies have also found that charitable giving can be increased by increasing the level of sympathy for the recipient (Small and Loewenstein, 2003; Kogut and Ritov, 2005; Small and Simonsohn, 2008). We therefore investigate the effect of emotions on giving behavior (Small and Verrochi, 2009). The positive emotion of empathic joy has also been found to be a key driver in establishing helping relationships. Smith et al. (1989) show that empathic persons are more likely to engage in helping behavior when they anticipate that the recipients' plight will be alleviated and that they will share their joy. Fisher et al. (2008) propose that the effectiveness of a recipient-focused advertisement is enhanced by the recipients' positive emotions, and that this effect is not present in non-recipient-focused advertising.

\subsection{Arousal}

Arousal is generally seen as an important factor in human psychology. Reviewing a large body of literature, Lang (2000, 2006a, 2006b) proposes a model of human information processing in which arousing content evokes more cognitive resources that can be allocated to information processing, resulting in increased attention and improved memory of the subject. Arousal is also linked to immediate behavioral inclinations, backed by emotional responses and an increase in reaction speed (Metcalfe and Mischel, 1999). The effect of arousal on helping behavior in emergency conditions is reported in multiple studies (Krebs, 1975; Gaertner and Dovidio, 1977) and conceptualized in a model by Piliavin et al. (1981). However, a large portion of this literature tends to refer to arousal in terms of an intense emotion, which includes other emotions in certain contexts.

While there exist many studies establishing the relationship between arousal, cognition, and behavior in general, there are fewer studies that relate to the effects of arousal on giving behavior. Kogut and Ritov (2005) report that people have greater willingness to help identified victims than anonymous ones, with identified victims evoking increased arousal and a greater tendency to donate. Dickert et al. (2011) show that mood is an important aspect of donation behavior, with people who experience strong negative arousal from information related to the victim being more likely to donate money.

\subsection{Donations by Others}

Many of our decisions are influenced by others. Herd behavior posits that individuals in a group imitate others' behaviors by observing their decisions (Banerjee, 1992). Silverman et al. (1984) find herd behavior in donations in their analysis of a 20-hour national telethon that announced the names of individuals pledging money and the total amount of money pledged. They found that contributions to the campaign were greater when contribution information was announced than when it was not provided. In economics, models of altruism incorporate the donations of others by admitting the possibility that utility can be obtained by one's own donation and also by the donations of others. These models are based on the assumption that people care about what others do and may alter their behavior based on this information (Hollander, 1990; Andreoni, 1990). 


\section{MODEL}

In this section we propose an economic utility model for donation behavior and develop the model likelihood using the Kuhn-Tucker conditions associated with constrained optimization.

\subsection{Direct Utility Specification}

Utility from individual $i$ 's donation decision is defined as:

$$
u\left(g_{i}, G, z_{i}\right)=\gamma_{1 \mathrm{i}} \ln \left(g_{i}+1\right)+\gamma_{2 \mathrm{i}} \ln (G)+\gamma_{3 \mathrm{i}} \ln \left(z_{i}+1\right)
$$

subject to

$$
\begin{gathered}
g_{i}+z_{i}=w_{i} \\
g_{i}+G_{-i}=G
\end{gathered}
$$

where $g_{i}$ is the amount of money donated by person $i . z_{i}$ is the amount of money not donated by person $i$. $w_{i}$ is the charitable donation budget for person $i . G_{-i}$ are the donations given prior to the donation by person $i$, assumed exogenous. $G$ denotes the total donations. The relative strength among the utility parameters $\left(\gamma_{1 \mathrm{i}} \geq 0, \gamma_{2 \mathrm{i}} \geq 0\right.$, and $\left.\gamma_{3 \mathrm{i}} \geq 0\right)$ influences the donation amount, with donations increasing in $\gamma_{1 \mathrm{i}}$ and $\gamma_{2 \mathrm{i}}$ over the outside good $\left(\gamma_{3 \mathrm{i}}\right)$ of private consumption.

Equation (1) allows for the possibility that utility is affected by the giving of others through $G$. If $\gamma_{1 \mathrm{i}}>0$ and $\gamma_{2 \mathrm{i}}=0$, the utility function reflects egoistic behavior as the utility from the donation does not depend on others. If $\gamma_{1 \mathrm{i}}=0$ and $\gamma_{2 \mathrm{i}}>0$, then the utility function reflects purely altruistic behavior as the utility from making a donation arises entirely from the total donation amount $G$, and not the individual's donation $g_{i}$. For $\gamma_{1 \mathrm{i}}>0$ and $\gamma_{2 \mathrm{i}}>0$, the function represents warm-glow utility that is a mixture of both egoistic and altruistic sources.

\subsection{Incorporating Message Variables}

We investigate the influence of variables identified as potentially influencing effectiveness of an appeal for a donation by relating them to parameters of the utility function. We denote the advertising attributes given at $t$ as $\mathbf{d}_{t}^{\prime}=\left(\mathrm{d}_{1 \mathrm{t}}, \mathrm{d}_{2 \mathrm{t}}, \mathrm{d}_{3 \mathrm{t}}\right)$, with $\mathrm{d}_{1 \mathrm{t}}=1$ if an advertisement is focused on the recipient, $d_{2 t}=1$ if the advertisement has positive emotional valence (e.g., displays happy individuals), and $\mathrm{d}_{3 \mathrm{t}}=1$ if the advertisement attempts to induce some form of arousal in the respondent, and zero otherwise. The advertising variables are incorporated into the model specification to allow for 2-way interactions:

$$
\begin{gathered}
\ln \left(\gamma_{1 \mathrm{it}}\right)=\beta_{0 \mathrm{i}}+\beta_{1 \mathrm{i}} \mathrm{d}_{1 \mathrm{t}}+\beta_{2 \mathrm{i}} \mathrm{d}_{2 \mathrm{t}}+\beta_{3 \mathrm{i}} \mathrm{d}_{3 \mathrm{t}}+\beta_{4 \mathrm{i}} \mathrm{d}_{1 \mathrm{t}} \mathrm{d}_{2 \mathrm{t}}+\beta_{5 \mathrm{i}} \mathrm{d}_{1 \mathrm{t}} \mathrm{d}_{3 \mathrm{t}}+\beta_{6 \mathrm{i}} \mathrm{d}_{2 \mathrm{t}} \mathrm{d}_{3 \mathrm{t}} \\
\ln \left(\gamma_{2 \mathrm{it}}\right)=0 \\
\ln \left(\gamma_{3 \mathrm{it}}\right)=\alpha_{0 \mathrm{i}}
\end{gathered}
$$

Positive $\beta_{\mathrm{i}}$ coefficients in (2) indicate an increased tendency to be egoistic, and negative coefficients indicate that the advertisement leads to an altruistic response. Since $\gamma_{2 \mathrm{i}}$ is set to one, the utility specification is technically a warm-glow specification in that no respondent can be purely egoistic in their response. However, as $\gamma_{1 \mathrm{i}}$ and $\gamma_{3 \mathrm{i}}$ become large, the utility function converges to a pure egoistic model of behavior. Larger values of $\alpha_{0 \mathrm{i}}$ indicate that the respondent obtains greater utility from consuming the outside good (non-giving), holding the other coefficients fixed. 


\subsection{Likelihood}

The marginal utilities associated with charitable giving $\left(\mathrm{g}_{\mathrm{it}}\right)$ and non-giving $\left(\mathrm{z}_{\mathrm{it}}\right)$ are:

$$
\begin{gathered}
u_{\text {git }}=\frac{\partial u}{\partial g_{i t}}=\frac{\gamma_{1 i t}}{g_{\text {it }}+1}+\frac{\gamma_{2 i t}}{g_{\text {it }}+G_{-i t}} \\
u_{\text {zit }}=\frac{\partial u}{\partial z_{i t}}=\frac{\gamma_{3 i t}}{z_{\text {it }}+1}
\end{gathered}
$$

The KT conditions associated with constrained utility maximization are:

$$
\begin{gathered}
\mathrm{u}_{\text {git }}=\mathrm{u}_{\mathrm{zit}} \text { if } \mathrm{g}_{\mathrm{it}}>0 \text { and } \mathrm{z}_{\mathrm{it}}>0 \\
\mathrm{u}_{\text {git }}<\mathrm{u}_{\mathrm{zit}} \text { if } \mathrm{g}_{\mathrm{it}}=0 \text { and } \mathrm{z}_{\mathrm{it}}>0 \\
\mathrm{u}_{\text {git }}>\mathrm{u}_{\mathrm{zit}} \text { if } \mathrm{g}_{\mathrm{it}}>0 \text { and } \mathrm{z}_{\mathrm{it}}=0
\end{gathered}
$$

We associated the error with the marginal utility of a donation, i.e., $\mathrm{u}_{\mathrm{git}} \exp \left(v_{\mathrm{it}}\right)$, with $v_{\mathrm{it}}$ assumed i.i.d. Normal $(0,1)$. Taking logarithms results in the likelihood:

$$
\begin{gathered}
\ln \left(\mathrm{u}_{\mathrm{zit}}\right)-\ln \left(\mathrm{u}_{\text {git }}\right)=v_{\text {it }} \text { if } \mathrm{g}_{\mathrm{it}}>0 \text { and } \mathrm{z}_{\mathrm{it}}>0 \\
\ln \left(\mathrm{u}_{\mathrm{zit}}\right)-\ln \left(\mathrm{u}_{\mathrm{git}}\right)>v_{\text {it }} \text { if } \mathrm{g}_{\mathrm{it}}=0 \text { and } \mathrm{z}_{\mathrm{it}}>0 \\
\ln \left(\mathrm{u}_{\mathrm{zit}}\right)-\ln \left(\mathrm{u}_{\mathrm{git}}\right)<v_{\text {it }} \text { if } \mathrm{g}_{\mathrm{it}}>0 \text { and } \mathrm{z}_{\text {it }}=0
\end{gathered}
$$

Therefore, the likelihood $l$ of the data is:

$$
\begin{aligned}
& l\left(\mathrm{~g}_{\mathrm{it}}, \mathrm{z}_{\mathrm{it}}\right)=\mathrm{I}\left(\mathrm{g}_{\mathrm{it}}>0, \mathrm{z}_{\mathrm{it}}>0\right) \phi\left(\ln \left(\mathrm{u}_{\mathrm{zit}}\right)-\ln \left(\mathrm{u}_{\mathrm{git}}\right)\right)|\mathrm{J}| \\
& \quad+\mathrm{I}\left(\mathrm{g}_{\mathrm{it}}=0, \mathrm{z}_{\mathrm{it}}>0\right) \Phi\left(\ln \left(\mathrm{u}_{\mathrm{zit}}\right)-\ln \left(\mathrm{u}_{\mathrm{git}}\right)\right) \\
& +\mathrm{I}\left(\mathrm{g}_{\mathrm{it}}>0, \mathrm{z}_{\mathrm{it}}=0\right)\left(1-\Phi\left(\ln \left(\mathrm{u}_{\mathrm{zit}}\right)-\ln \left(\mathrm{u}_{\mathrm{git}}\right)\right)\right)
\end{aligned}
$$

where $|\mathrm{J}|$ is a Jacobian to transform the density of the error term $v_{\text {it }}$ to the density of the observed data $g_{\mathrm{it}}$ :

$$
J=\frac{\partial v_{\text {it }}}{\partial g_{\text {it }}}=\left[\frac{\frac{\gamma_{1 \text { it }}}{\left(g_{\text {it }}+1\right)^{2}}+\frac{\gamma_{2 \text { it }}}{\left(g_{\text {it }}+G_{-i t}\right)^{2}}}{\frac{\gamma_{1 i t}}{\left(g_{\text {it }}+1\right)}+\frac{\gamma_{2 i t}}{\left(g_{\text {it }}+G_{-i t}\right)}}\right]+\frac{1}{\left(z_{\text {it }}+1\right)}
$$

Heterogeneity is introduced through a continuous random effects distribution:

$$
\theta_{\mathrm{i}}^{\prime}=\left(\alpha_{0 \mathrm{i}}, \beta_{0 \mathrm{i}}, \beta_{1 \mathrm{i}}, \ldots, \beta_{6 \mathrm{i}}\right) \sim \mathrm{N}(\boldsymbol{\mu}, \boldsymbol{\Sigma})
$$

Estimation was carried out using a Bayesian MCMC algorithm (Rossi et al., 2005) with noninformative priors. We ran the Markov chain for 20,000 iterations and used last 5,000 draws for summarizing posterior distributions.

\section{EMPIRICAL ANALYSIS}

Data were collected as part of an incentive-aligned lottery experiment (Ding et al., 2005) in South Korea. Respondents were recruited from a campus population, representing a typical '20-something' population of young adults. Sixty percent of the participants were male with an 
average age of 22.5 years. Participants were provided with a probable windfall of KRW 100,000 (South Korean Won), about $\$ 100$, and invited to make a donation to a charity. They were told that if they won the lottery, all money not given to the charity would be paid directly to them at the end of the study. Each of 206 respondents were provided with 16 descriptions of charities, described below. Results of the lottery for each round were announced after the respondents indicated the amount of their intended donation $\left(\mathrm{g}_{\mathrm{it}}\right)$.

"In case you win this round, you may donate money to the organization above. The amount you commit to donate does not affect the chance of winning. Should you win this round, how much of the KRW 100,000 would you like to donate? If you don't want to donate, please enter ' 0 ' in the box."

Participants were informed about winning the lottery after each of the 16 rounds of the experiment. For each round, we assume that $w_{i t}=$ KRW 100,000. All money not donated to a charity $\left(\Sigma_{\mathrm{t}} \mathrm{z}_{\mathrm{it}}\right)$ was paid directly to the respondent at the conclusion of the study. Each participant won the lottery four times.

\subsection{Attributes and Levels}

Table 2 provides a summary of the manipulated attributes in the study. In addition to the three attributes discussed above coded as dummy variables, i.e., recipient-focused, positive emotional valence and arousal, the amount of donations by others was used as the fourth design variable and included as a continuous variable in the model specification $\left(G_{-i t}\right)$. The amount donated by others took on either high or low values plus some random error in order for the amount reported to be different over the $2^{4}=16$ design points.

Table 2

Message Attribute Levels and Coding

\begin{tabular}{|c|c|c|c|c|}
\hline Attribute Levels & $\begin{array}{l}\text { Recipient-Focused } \\
\left(d_{1}\right)\end{array}$ & $\begin{array}{l}\text { Emotional Appeal } \\
\qquad\left(d_{2}\right)\end{array}$ & $\begin{array}{c}\text { Arousal } \\
\left(d_{3}\right)\end{array}$ & $\begin{array}{l}\text { Donations by Others } \\
\qquad\left(G_{-i}\right)\end{array}$ \\
\hline Recipient-focused & 1 & & & \\
\hline Non-recipient-focused & 0 & & & \\
\hline Present & & 1 & & \\
\hline Absent & & 0 & & \\
\hline Present & & & 1 & \\
\hline Absent & & & 0 & \\
\hline High & & & & $\sim$ KRW 1,000,000,000 \\
\hline Low & & & & $\sim$ KRW 500,000 \\
\hline
\end{tabular}

Figure 1 is an appeal that is not focused on the recipient and is not emotionally charged, but does attempt to arouse the reader in the lower right portion of the figure with the use of optimistic statements and exclamation points. In contrast, Figure 2 is recipient-focused and makes a positive emotional appeal by showing a happy school child. This appeal does not attempt to arouse the reader. The attributes levels displayed in Table 2 were systematically varied across the 16 experimental conditions, with half reporting a high level of donations by others and the other half reporting lower levels. 
Figure 1

Non-recipient-focused, non-positive, arousal advertisement

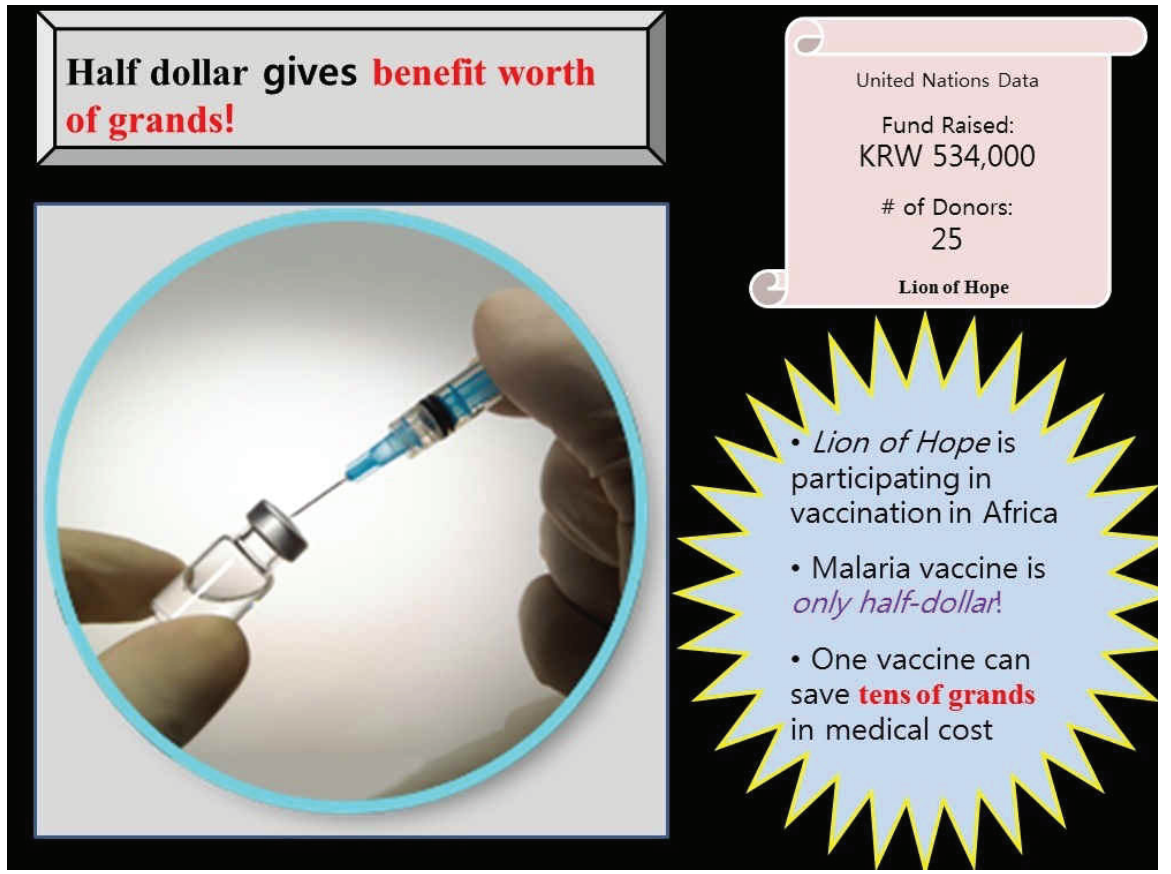

Figure 2

Recipient-focused, positive, non-arousal advertisement.

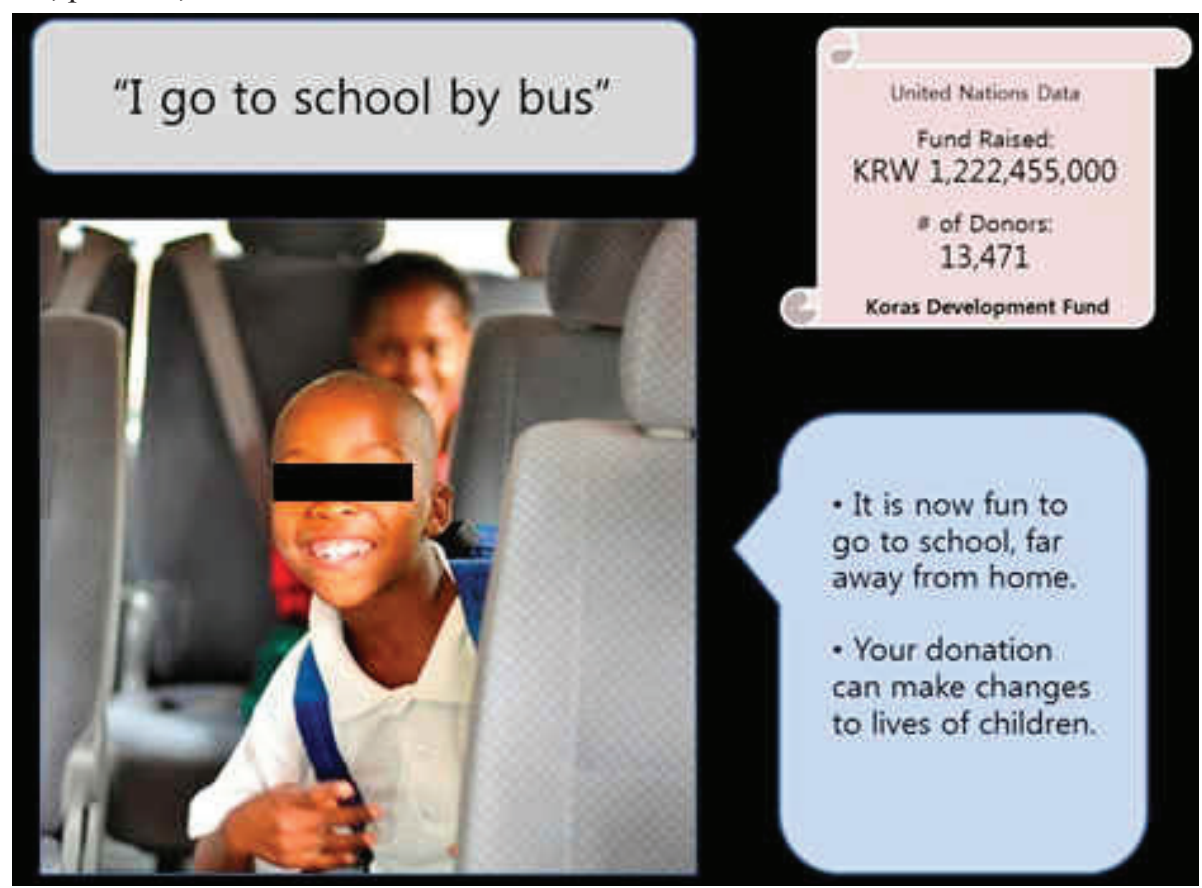

\subsection{Descriptive Statistics}

206 individuals participated in the experiment, each providing 16 responses to charitable appeals for a total of 3,296 observations with which to estimate the model. Approximately $16 \%$ of the observations were corner solutions where respondents donated either nothing or all of their budget to the charity. Respondents mostly allocated their budget as a mixture of donation $\left(g_{i t}\right)$ and non-donation $\left(z_{i t}\right)$, i.e., an interior solution. Figure 3 displays the distribution of donations in our data. The average donation was KRW 27,400, or about $\$ 27.00$. The maximum and minimum 
were KRW 100,000 and 0, respectively. On average, participants elected to make a donation $84 \%$ of the time.

The marginal utility of giving, $u_{\text {git }}$, in equation (3) decreases when donors are informed of high donation amounts by others, $G_{-i t}$. Table 3 displays donation amounts in our data for high and low values of $G_{-i t}$. We find that the experimental data agree with this property, providing evidence in line with our utility specification.

\section{Figure 3}

Distribution of Donations $\left(g_{i t}\right)$

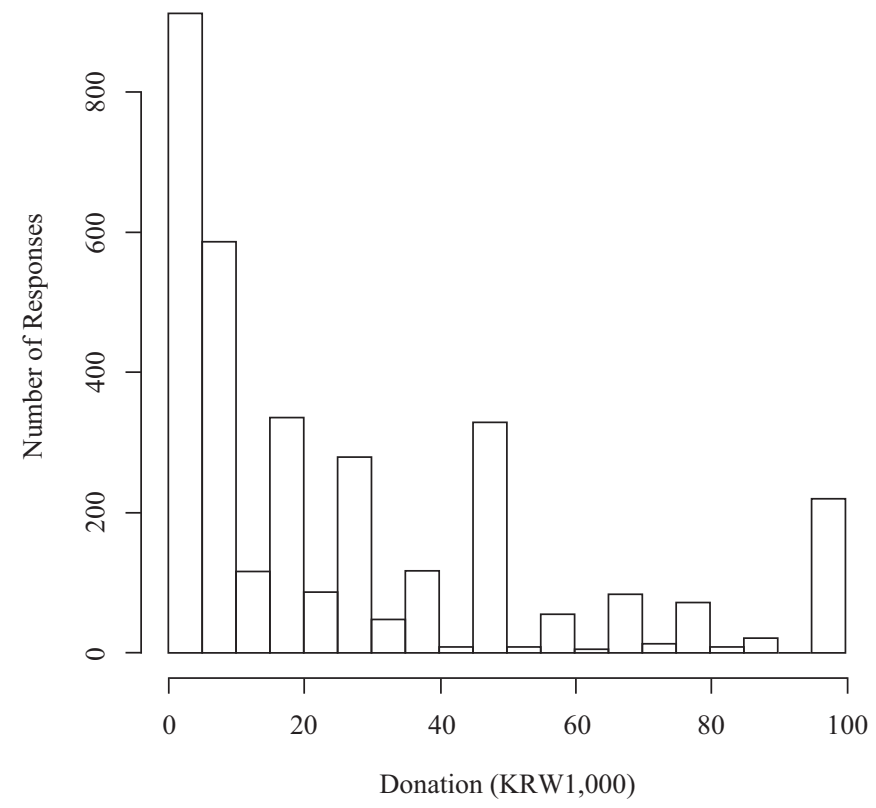

Table 3

Donations by Others' Giving $\left(G_{-i t}\right)$

\begin{tabular}{|c|c|c|c|}
\hline Condition & $\begin{array}{c}\text { Total Donations } \\
\text { (KRW 1,000) }\end{array}$ & $\begin{array}{c}\text { Mean Donations } \\
(\text { KRW 1,000) }\end{array}$ & $\begin{array}{c}\text { Median Donations } \\
(\text { KRW 1,000) }\end{array}$ \\
\hline$G_{-i t}$ low & 46,642 & 28.3 & 20 \\
\hline$G_{-i t}$ high & 43,909 & 26.6 & 15 \\
\hline
\end{tabular}

\subsection{Alternative Models}

Fourteen observations per respondent were used to estimate the model and two observations were reserved for predictive testing. We compared our proposed model to four alternative specifications. The first two models are nested within our proposed model. The first (M1) is a model of pure altruism where the utility function is specified as:

$$
\mathrm{u}\left(g_{\mathrm{i}}, \mathrm{G}, z_{\mathrm{i}}\right)=\gamma_{2 \mathrm{i}} \ln \left(g_{\mathrm{i}}+G_{-i}\right)+\gamma_{3 \mathrm{i}} \ln \left(z_{\mathrm{i}}+1\right)
$$

The second model (M2) reflects pure egoistic behavior in that the contribution amount of others does not factor into one's giving behavior:

$$
\mathrm{u}\left(g_{\mathrm{i}}, z_{\mathrm{i}}\right)=\gamma_{1 \mathrm{i}} \ln \left(g_{\mathrm{i}}+1\right)+\gamma_{3 \mathrm{i}} \ln \left(z_{\mathrm{i}}+1\right)
$$

For the first two alternative models, message attributes were used to allow for variation in the marginal utility parameters. 
The third (M3) and fourth (M4) models are purely descriptive models of the data and employ a regression specification that does not distinguish corner from interior solutions. The third alternative model specifies a log-linear model of the data with a slight offset added to the dependent variable so that the logarithmic specification is valid:

$$
\begin{gathered}
\ln \left(g_{i \mathrm{t}}+.01\right)=\beta_{0 \mathrm{i}}+\beta_{1 \mathrm{i}} \mathrm{d}_{1 \mathrm{t}}+\beta_{2 \mathrm{i}} \mathrm{d}_{2 \mathrm{t}}+\beta_{3 \mathrm{i}} \mathrm{d}_{3 \mathrm{t}}+ \\
\beta_{4 \mathrm{i}} \mathrm{d}_{1 \mathrm{t}} \mathrm{d}_{2 \mathrm{t}}+\beta_{5 \mathrm{i}} \mathrm{d}_{1 \mathrm{t}} \mathrm{d}_{3 \mathrm{t}}+\beta_{6 \mathrm{i}} \mathrm{d}_{2 \mathrm{t}} \mathrm{d}_{3 \mathrm{t}}+\beta_{7 \mathrm{i}} \ln \left(G_{-\mathrm{it}}\right)+\varepsilon_{\mathrm{it}}
\end{gathered}
$$

The fourth alternative model is a saturated log-linear model that allows for a three-way interaction:

$$
\begin{gathered}
\ln \left(g_{i \mathrm{t}}+.01\right)=\beta_{0 \mathrm{i}}+\beta_{1 \mathrm{i}} \mathrm{d}_{1 \mathrm{t}}+\beta_{2 \mathrm{i}} \mathrm{d}_{2 \mathrm{t}}+\beta_{3 \mathrm{i}} \mathrm{d}_{3 \mathrm{t}}+ \\
\beta_{4 \mathrm{i}} \mathrm{d}_{1 \mathrm{t}} \mathrm{d}_{2 \mathrm{t}}+\beta_{5 \mathrm{i}} \mathrm{d}_{1 \mathrm{t}} \mathrm{d}_{3 \mathrm{t}}+\beta_{6 \mathrm{i}} \mathrm{d}_{2 \mathrm{t}} \mathrm{d}_{3 \mathrm{t}}+\beta_{7 \mathrm{i}} \mathrm{d}_{1 \mathrm{t}} \mathrm{d}_{2 \mathrm{t}} \mathrm{d}_{3 \mathrm{t}}+\beta_{8 \mathrm{i}} \ln \left(G_{-i t}\right)+\varepsilon_{\mathrm{it}}
\end{gathered}
$$

All models employed a Normal distribution of heterogeneity and were estimated with Bayesian MCMC using the same default priors.

The results of the model fit for the proposed model and benchmark models are summarized in Table 4. The proposed model and the first two benchmark models (M1 and M2) are based on likelihoods that are a combination of mass points and density contributions. We report the $\log$ marginal densities (LMD) for these models. The two descriptive models (M3 and M4) have likelihoods that only involve densities, and therefore cannot be directly compared to the other models in terms of in-sample fit. However, a comparison of all models is possible using the holdout data, which we compare using the mean squared error (MSE).

Table 4

Model Fit

\begin{tabular}{l|c|c|c|c}
\multicolumn{1}{|c}{ Model } & $\begin{array}{c}\text { Coefficients } \\
\text { per Respondent }\end{array}$ & In-Sample LMD & \multicolumn{2}{c}{ Out-of-Sample } \\
\hline M0: Proposed Model & 8 & $-10,992$ & $-1,996$ & 1096.3 \\
\hline M1: Pure Altruistic & 7 & $-29,373$ & $-14,439$ & 7979.0 \\
\hline M2: Pure Egoistic & 7 & $-11,081$ & $-2,204$ & 1084.0 \\
\hline M3: Log-Linear & 8 & - & - & 2008.1 \\
\hline M4: Saturated Log-Linear & 9 & - & - & 5631.0
\end{tabular}

The proposed model outperforms all the benchmark models in both in-sample and out-ofsample log marginal density (LMD). Comparison of M0 to M1 indicates that an individual's donation decision cannot be explained entirely by the purely altruistic model. Comparison of M0 to M3 and M4 supports the use of the proposed economic framework relative to a flexible model for predicting donations. We note that the fit of the proposed model M0 to the pure egoistic model M2 is similar, with M0 favored using the out-of-sample LMD, but not favored using the MSE fit criteria. We further examine the benefit of employing the proposed model in the discussion section below.

\subsection{Parameter Estimates}

Posterior estimates of parameters for the proposed model are reported in Table 5. Reported are the posterior mean of the mean of the random-effects distribution $(\mu)$ along with the 
random-effects covariance matrix $(\Sigma)$. The posterior standard deviation of all coefficients is approximately 0.10 . Covariances (off-diagonal elements) in the random-effect distribution are near zero, indicating that the model is well-identified. Diagonal elements of $\Sigma$ are approximately equal to one, indicating heterogeneity in all model parameters.

Estimates of the mean of the random-effect matrix $(\mu)$ indicate the following. First, the estimate of $\beta_{1}$ and $\beta_{3}$ are both positive, indicating that main effects for advertisements that are recipient-focused and attempt to arouse the respondent lead to more egoistic responses and greater giving. The positive effect of recipient-focused advertising is consistent with existing literature (Goffrnan, 1959; Leary and Kowalski, 1990; White and Peloza, 2009), although its distinction as egoistic has not been made.

Table 5

Posterior Mean $(\mu)$ and Covariance Matrix $(\Sigma)$ of Random Effects

\begin{tabular}{cccc|c|c|c|c|c|c}
\hline Parm. & Mean & $\boldsymbol{\alpha}_{0}$ & $\boldsymbol{\beta}_{0}$ & $\boldsymbol{\beta}_{1}$ & $\boldsymbol{\beta}_{2}$ & $\boldsymbol{\beta}_{3}$ & $\boldsymbol{\beta}_{4}$ & \multicolumn{1}{c}{$\boldsymbol{\beta}_{5}$} & $\boldsymbol{\beta}_{6}$ \\
\hline$\alpha_{0}$ & -0.56 & 1.44 & 0.01 & -0.02 & -0.07 & -0.22 & -0.06 & 0.08 & -0.05 \\
$\beta_{0}$ & -2.41 & & 1.44 & -0.04 & 0.09 & -0.03 & 0.00 & -0.02 & 0.06 \\
\hline$\beta_{1}$ & 0.55 & & & 0.95 & -0.02 & -0.11 & -0.17 & -0.04 & -0.03 \\
\hline$\beta_{2}$ & 0.09 & & & & 0.94 & 0.05 & -0.17 & -0.07 & -0.15 \\
\hline$\beta_{3}$ & 0.50 & & & & & 0.87 & 0.04 & -0.21 & -0.12 \\
\hline$\beta_{4}$ & -0.42 & & & & & & 0.95 & -0.09 & -0.12 \\
$\beta_{5}$ & -0.14 & & & & & & & 0.98 & -0.05 \\
\hline$\beta_{6}$ & -0.74 & & & & & & & & 0.90 \\
\hline
\end{tabular}

Two of the two-way interaction terms $\left(\beta_{4}\right.$ and $\left.\beta_{6}\right)$ are estimated to be negative. The coefficient $\beta_{4}$ is associated with the interaction between a recipient-focused advertisement $\left(\mathrm{d}_{1}\right)$ and it being positively valenced $\left(\mathrm{d}_{2}\right)$. The negative coefficient means that the relative marginal utility for making a donation, $u_{\text {git }}$, becomes more altruistic when these effects are present. Thus, recipientfocused advertisements lead to greater egoistic giving, primarily in the presence of non-positive emotional valence (e.g., showing recipients in distress) but not in the presence of positive emotional valence (e.g., showing happy or thankful recipients).

The coefficient $\beta_{6}$ is also negative and associated with the interaction between positive emotional valence $\left(\mathrm{d}_{2}\right)$ and arousal $\left(\mathrm{d}_{3}\right)$. The presence of arousal in an advertisement is only effective, on average, when emotional valence is not positive. In other words, a call to immediate action in an advertisement is more effective when showing recipients in distress. This finding is consistent with previous research showing that the effectiveness of a recipient-focused advertisement is enhanced by a recipient's negative emotions (Fisher et al., 2008; Small and Verrochi, 2009), and that empathic arousal leads to altruistic helping (Davis, 1994a). 
Table 6

Source of Marginal Utility

\begin{tabular}{c|c|c|c|cc} 
Campaign & $\begin{array}{r}\text { Recipient-Focused } \\
\left(d_{1}\right)\end{array}$ & $\begin{array}{c}\text { Emotional Appeal } \\
\left(d_{2}\right)\end{array}$ & $\begin{array}{c}\text { Arousal } \\
\left(d_{3}\right)\end{array}$ & $\begin{array}{c}\text { Median Ratio of Altruistic to Egoistic Marginal Utility } \\
\left(G_{-i t} \text { Low }\right)\end{array}$ & $\left(G_{-i t}\right.$ High $)$ \\
\hline 1 & 0 & 0 & 0 & 0.2537 & 0.0001 \\
\hline 2 & 1 & 0 & 0 & 0.2113 & 0.0001 \\
\hline 3 & 0 & 1 & 0 & 0.2330 & 0.0001 \\
\hline 4 & 0 & 0 & 1 & 0.2055 & 0.0001 \\
\hline 5 & 1 & 1 & 0 & 0.2219 & 0.0001 \\
\hline 6 & 1 & 0 & 1 & 0.1658 & 0.0001 \\
\hline 7 & 0 & 1 & 1 & 0.2540 & 0.0001 \\
\hline 8 & 1 & 1 & 1 & 0.2298 & 0.0001 \\
\hline
\end{tabular}

Table 6 displays the estimated contribution of the altruistic to egoistic sources of marginal utility for each of the experimental conditions. From equation (3) we see that the marginal utility of making a donation has two terms - an egoistic term not dependent on the amount that others have given, $G_{-i t}$, and an altruistic term that is dependent on the contributions to date. The entries in Table 6 are the median values of marginal utility calculated over the posterior distribution of individual-level parameters. As expected, we find that for high values of $G_{-i t}$ the altruistic motivation for making a donation is near zero. Respondents with an altruistic motivation can already see that the need depicted in the appeal is already taken care of when $G_{-i t}$ is high, reducing their incentive to make a donation. However, when contributions to date are low, the altruistic motive becomes more pronounced, producing a contribution to marginal utility that is similar in magnitude to the egoistic effect.

\section{POLICY EXPERIMENTS}

Our economic model for donation behavior fits the data best and yields results that are consistent with previous findings in the literature regarding effective attributes for increased giving, egoistic and altruistic behavior. The advantage of our model, however, is that it provides individual-level estimates of the effects of appeal attributes on these aspects of giving behavior. In this section we explore use of these individual-level estimates to improve donations. We examine three issues of interest to campaign managers: i) configuring the best message; ii) message timing; and iii) determining optimal targeting of donors to maximize receipts.

\subsection{Message Configuration}

We find in our analysis that the focus of the appeal (recipient or non-recipient), its positive emotional appeal (present or absent) and arousal factors (present or absent) had an effect on the marginal value of egoistic utility. We define the best advertisement as the one that generates the greatest contribution amount across respondents $(i)$ over different combinations of these effects:

$$
\underset{\mathrm{d}}{\operatorname{argmax}} \sum_{\mathrm{i}} \mathrm{g}_{\mathrm{i}}\left(\mathrm{d}_{1}, \mathrm{~d}_{2}, \mathrm{~d}_{3}\right)
$$

We calculate the expected contribution of each individual assuming that donors are contacted in descending order of contribution. That is, the first person contacted at $t=1$ is identified as 
having the greatest value of $g_{i}$ for $G_{-i, t=1}=0$. The second person has the greatest value of $g_{i}$ for the remaining respondents with $G_{-i, t=2}=g_{1}$, where $g_{1}$ is the contribution of the first respondent. The third person has the greatest value of $g_{i}$ among those not yet contributing when we set $G_{-i, t=3}=g_{1+} g_{2}$, and so on.

Table 7

Optimal Campaign Message

\begin{tabular}{c|c|c|c|c|}
\hline Campaign & $\begin{array}{c}\text { Recipient-Focused } \\
\left(d_{1}\right)\end{array}$ & $\begin{array}{c}\text { Emotional Appeal } \\
\left(d_{2}\right)\end{array}$ & $\begin{array}{c}\text { Arousal } \\
\left(d_{3}\right)\end{array}$ & $\begin{array}{c}\text { Total Donations } \\
(\text { KRW 1,000) }\end{array}$ \\
\hline 1 & 0 & 0 & 0 & 4,317 \\
\hline 2 & 1 & 0 & 0 & 5,773 \\
\hline 3 & 0 & 1 & 0 & 4,779 \\
\hline 4 & 0 & 0 & 1 & 5,736 \\
\hline 5 & 1 & 1 & 0 & 5,092 \\
\hline 6 & 1 & 0 & 1 & 7,798 \\
\hline 7 & 0 & 1 & 1 & 4,625 \\
\hline 8 & 1 & 1 & 1 & 5,200 \\
\hline
\end{tabular}

Campaign message six is found to produce the greatest total donation. This message is focused on the recipient, has non-positive emotion and has elements of arousal that call respondents to action. In general, we find there are large differences among the different campaigns, and that the coefficient estimates reported in Table 5 result in large variation in the expected donations of respondents. In addition, we find that the optimal campaign message six is the campaign that has the lowest ratio of altruistic to egoistic marginal utility (see Table 6). This advertisement graphically shows the plight of malnourished and neglected children.

\subsection{Timing}

Our analysis of the source of marginal utility in Table 6 indicates that altruistic motivations for giving are diminished as it becomes known that others have already made contributions to a charitable cause. This raises the issue of the value of sequencing a series of appeals to prospective donors that first appeals to altruistic individuals, and then later to egoistic individuals so that altruistic people do not feel that people have not already contributed enough to cause.

We value the altruistic component of utility by comparing campaign contributions from a sequence of appeals that either begin with an advertisement that is relatively more appealing to an egoistic motive versus an altruistic motive as measured in Table 6 . Table 8 displays results for alternative sequences and comprises two altruistic campaigns ( 1 and 3 ) and two egoistic campaigns (2 and 4). For each sequence, the respondent with the highest contribution amount, $\mathrm{g}_{1}=\mathrm{g} *$, is considered to be the first contributor, and we set $G_{-i, t=2}=g_{1}$ as before. The values of $\mathrm{g}^{*}$ are recalculated for each remaining respondent, with the highest contribution amount set equal to $\mathrm{g}_{2}$ and $G_{-i, t=2}=\mathrm{g}_{1}+\mathrm{g}_{2}$, and so on. When the number of respondents with the highest contributions equals half the sample, the appeal for donations is changed to that of the second campaign and associated contributions are determined for each respondent. 
Table 8

Optimal Campaign Timing

\begin{tabular}{|c|c|c|c|c|}
\hline \multicolumn{2}{|c|}{ First Campaign } & \multicolumn{2}{|c|}{ Second Campaign } & Total Donations (KRW 1,000) \\
\hline \multirow{4}{*}{ High $\gamma_{1}$ : } & 2 & \multirow{4}{*}{ Low $\gamma_{1}$ : } & 1 & 5,248 \\
\hline & 2 & & 3 & 5,382 \\
\hline & 4 & & 1 & 5,274 \\
\hline & 4 & & 3 & 5,373 \\
\hline \multirow{4}{*}{ Low $\gamma_{1}$ : } & 1 & \multirow{4}{*}{ High $\gamma_{1}$ : } & 2 & 5,332 \\
\hline & 3 & & 2 & 5,456 \\
\hline & 1 & & 4 & 5,406 \\
\hline & 3 & & 4 & 5,578 \\
\hline
\end{tabular}

The top portion of Table 8 displays results for the first campaign having relatively higher marginal utility from egoistic motives (high $\gamma_{1}$ ) than from the second campaign (see Table 6). We note that the average differences of the ratio of altruistic to egoistic marginal utility among the campaigns are relatively small. Yet, these differences translate into consistently higher total donations when the campaign is led with a less egoistic appeal, ranging from 1-4\%. These results are due to heterogeneity in the population, and people selected for inclusion in a campaign when their contribution $g_{i}$ is high. The results are also dependent on aspects of the appeals and will vary depending on their quality. Our goal, here, is to demonstrate the value in leading campaigns with an altruistic-oriented versus an egoistic-oriented appeal.

\subsection{Targeting}

A more aggressive estimate of the value of knowing the underlying motivation for making a contribution is revealed when it is possible to fully customize others to the individual. This may occur when a firm has a history of interaction with respondents and can use past information to calibrate our model.

Table 9 reports results from using each of the various campaigns for the entire population, and the fraction of the population for which each campaign is best. The results are reported for two strategies - one in which the donations of others $\left(G_{-i t}\right)$ are accumulated by first approaching people with the highest contributions $g_{i}$ and another where appeals are first made to those with the smallest contributions. As reported in Table 8, we again find value in approaching people with smaller donation amounts first so that their altruistic motive is not diminished by the donations of others. 
Table 9

Donations from a Fully Customized Campaign

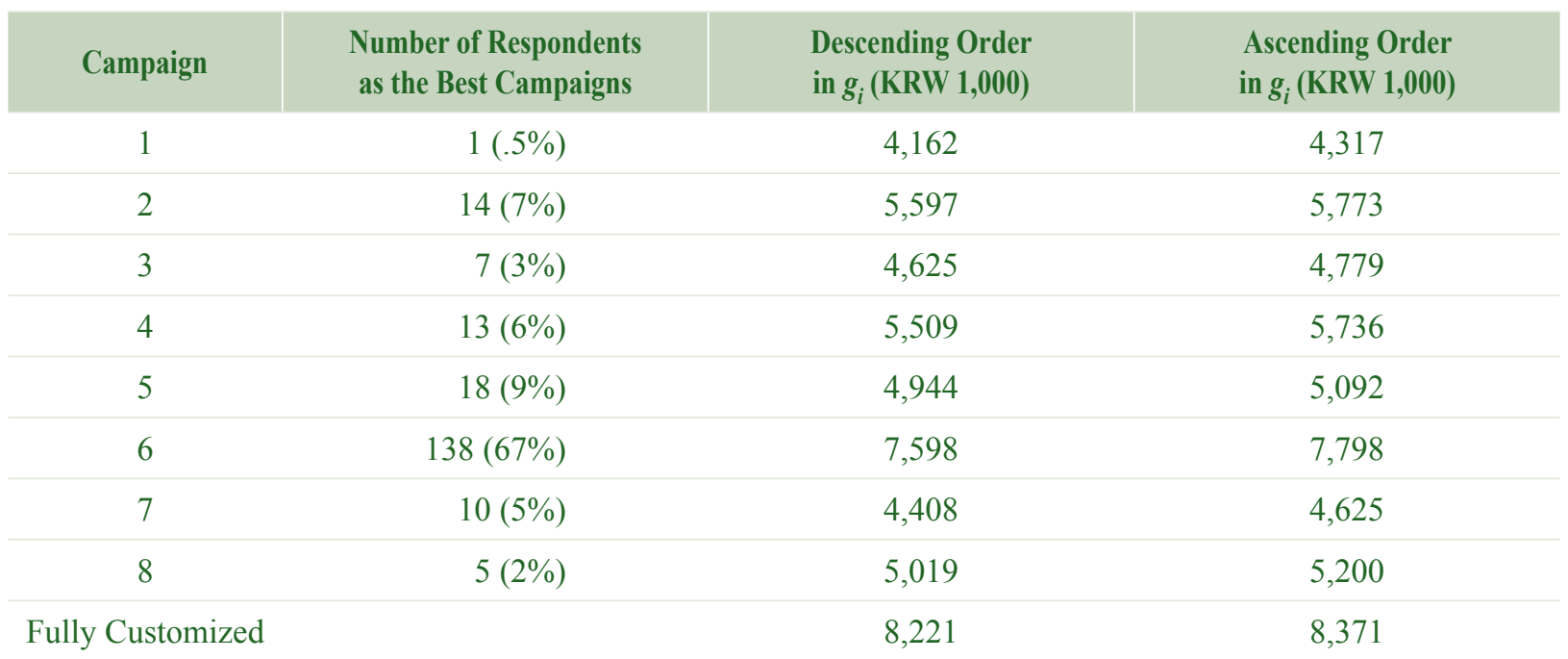

We find that the best campaign (6) is not uniformly favored among all respondents. Sixtyseven percent of the respondents are predicted to have maximum donation when exposed to this campaign, with the remaining 33\% spread over the other seven campaigns. The total amount of giving is increased to about 8,300 (KRW 1,000) under full customization, or about a 7-8\% increase over campaign six alone.

\section{CONCLUSIONS}

\subsection{Summary and Discussion}

In this paper we present an economic analysis of charitable donations that nests altruistic and egoistic aspects of giving. We relate characteristics of appeals to model parameters and investigate the effect of these appeal attributes on the aspects of giving behavior. The findings are as follows:

First, an advertising message for donation becomes more persuasive and contributes more to the propensity for giving when it is recipient-focused than non-recipient-focused. Second, an ad message with higher arousal also leads to an increase in donation. Third, we find no significant effect of the presence (absence) of emotional appeals in the message on the giving decision. Finally, it is important to note that there are significant interactions among the message attributes. We find that recipient-focused appeals with elements of arousal lead to heightened levels of giving, consistent with past research. We also find that the emotional aspect of an advertisement plays an interactive role with being recipient-focused and arousal so their effects are primarily present in advertisements with non-positive valence.

The results of our study serve to validate the use of the proposed utility function (equation 1) for understanding donation behavior. We find that it fits better than descriptive models, being able to better capture altruistic giving where donations decline when respondents know that other donors have already given to a cause. This effect is difficult to capture in a descriptive linear model without including all possible interactions, where we find that parameter estimates become unstable. We find that the altruistic giving effect (reduced giving when others are known to have already given) is more efficiently captured with our utility-based model.

We also find substantial within-respondent variation in giving, which can be attributed to variation in altruistic versus egoistic sources of utility. While prior research has documented the presence of situational factors influencing altruistic giving (Small et al., 2007), effects due to the campaign message have not previously been measured in a way that separates within- from 
across-respondent variation in response. We find coefficients associated with aspects of the campaign to be large and heterogeneous among respondents (see Table 5). Our model allows us to show value in the customization and timing of different appeals for donations.

Coupling with the heterogeneity across the potential donors in the message effects, various policy guidelines can be explored for non-profit organizations. Based on the estimation results of our utility model, we summarize managerial implications in the area of timing, targeting, and customization.

First, in designing the sequence for different campaigns (i.e., more appealing to egoistic motives versus altruistic motives), a campaign manager gets better off by offering a less egoistic campaign first and moving on to a more egoistic campaign later. This is because the altruistic motivations for giving are diminished as people learn that others already made donations to a charitable cause. Therefore, total donations are expected to be higher when the campaign uses a less egoistic appeal.

Second, regarding the targeting decision on whom and when to target, it is better to follow the ascending order (i.e., targeting individuals with smaller donations at an early stage) than to implement the descending order. We find that donors with relatively high altruistic motives tend to give smaller amounts, and that there is economic value in first soliciting donations from them than from egoistic donors who tend to give more. We note that this strategy is counter to many donation campaigns that first attempt to line-up big donors before reaching out to others. An interesting topic of future research would be whether the decision to go after big donors first is driven by demand-side considerations of giving by the donors or by supply-side considerations of the firm that wants to ensure success of the campaign during its early stage.

Finally, considering the substantive amount of heterogeneity, we find no single campaign that works best for every individual in our analysis. This offers an opportunity for additional donations gained by offering a customized campaign, i.e., matching the best campaign for each individual. Under the full customization, the total amount of giving is increased by $7-8 \%$ over the best single campaign alone.

\subsection{Limitations and Future Research}

There are some limitations in the current study. First, the analysis is based on the survey data from a conjoint experiment. Thus subjects are samples from university students, not able to perfectly represent all of the potential donors in the market. Replication of the study with actual donation data would be desirable to evaluate external validity of the effects learned in this paper. Secondly, our empirical analysis is based on consumer reactions to appeals requiring a onetime, immediate response. We believe that appeals for forming an on-going relationship with the recipient (e.g., World Vision http://www.worldvision.org) are likely to be more successful with stimuli showing the recipients happy and smiling rather than sad and starving. Our empirical findings may not translate to settings where the nature of the interaction with the donor is longterm, and additional research is needed in applying the model to other settings.

There are many other extensions to our model that can be addressed in future research. One avenue is exploring the variation in the social environment of giving behavior, and comparing the size of this effect to those associated with the appeal. Our data came from an experimental setting where this variation was not observed, and the effects of year-end giving during the holidays, or alternatively at the end of the tax year, are interesting extensions to the model.

Another extension is the issue of complementarity in a person's utility of donation behavior. Complementarity reflects synergistic effects among different donation opportunities. Given that it is not surprising to see individuals who donate to different charities, or volunteer across multiple activities; modeling the complementarity among giving behaviors is an important contribution to campaign management by identifying likely prospects based on their contributions to related campaigns. 


\section{ACKNOWLEDGEMENTS}

The first two authors appreciate 2012 and 2013 KAIST Business School Faculty Research Grant. Jaehwan Kim is grateful for the research grant from Korea University Business School.

\section{References}

Andreoni, J. (1989) 'Giving with impure altruism: Applications to charity and ricardian equivalence', The Journal of Political Economy, pp. 1447-1458.

Andreoni, J. (1990) 'Impure altruism and donations to public goods: a theory of warm-glow giving', The Economic Journal, 100, 401, pp. 464-477.

Arnett, D.B., German, S.D. and Hunt, S.D. (2003) 'The identity salience model of relationship marketing: the case of nonprofit marketing', Journal of Marketing, April, 67, pp. 89-105.

Bagozzi, R.P. and Moore, D.J. (1994) 'Public service advertisements: Emotions and empathy guide prosocial behavior', Journal of Marketing, pp. 56-70.

Banerjee, A.V. (1992) 'A simple model of herd behavior', The Quarterly Journal of Economics, 107, 3, pp. $797-817$.

Batson, C.D. (1987) 'Prosocial motivation: Is it ever truly altruistic?', Advertising and Experimental Social Psychology, 20, pp. 65-122.

Batson, C.D. (1990) 'How social an animal? the human capacity for caring', American Psychologist, 45, 3, pp. 336-346.

Batson, C.D., Dyck, J.L., Brandt, J.R., Batson, J.G., Powell, A.L., McMaster, M.R. and Grifftt, C. (1988) 'Five studies testing two new egoistic alternatives to the empathy-altruism hypothesis', Journal of personality and social psychology, 55, 1, pp. 52-77.

Batson, C.D., Sager, K., Garst, E., Kang, M., Rubchinsky, K. and Dawson, K. (1997) 'Is empathy-induced helping due to self-other merging?', Journal of Personality and Social Psychology, 73, 3, pp. 485-509.

Baumeister, R.F. (1982) 'A self-presentational view of social phenomena', Psychological bulletin, 91, 1, pp. 3-26.

Becker, G. (1974) 'A theory of social interactions', Journal of Political Economy, 82, 6, pp. 1063-1093.

Bendapudi, N., Singh, S.N. and Bendapudi, V. (1996) 'Enhancing helping behavior: An integrative framework for promotion planning', Journal of Marketing, pp. 33-49.

Brunel, F.F. and Nelson, M.R. (2000) 'Explaining gendered responses to "help-self" and "help-others" charity ad appeals: The mediating role of world-views', Journal of Advertising, 29, 3, pp.15-28.

Cialdini, R.B., Brown, S.L., Lewis, B.P., Luce, C. and Neuberg, S.L. (1997) 'Reinterpreting the empathy-altruism relationship: When one into one equals oneness', Journal of personality and social psychology, 73, 3, pp. 481-494.

Cialdini, R.B., Schaller, M., Houlihan, D., Arps, K., Fultz, J. and Beaman, A.L. (1987) 'Empathy-based helping: Is it selflessly or selfishly motivated?', Journal of personality and social psychology, 52, 4, pp. 749-758.

Coke, J.S., Batson, D.C. and McDavis, K. (1978) 'Empathic mediation of helping: A two-stage model', Journal of Personality and Social Psychology, 36, 7, pp. 752-766.

Davis, M.H. (1994a) Empathy: A social psychological approach, Westview Press.

Davis, M.H. (1994b) Helping and empathy: taking the multi-dimensional view, American Marketing Association.

DellaVigna, S., List, J.A. and Malmendier, U. (2012) 'Testing for altruism and social pressure in charitable giving', The Quarterly Journal of Economics, 127, 1, pp. 1-56.

Dickert, S., Sagara, N. and Slovic, P. (2011) 'Affective motivations to help others: A two-stage model of donation decisions', Journal of Behavioral Decision Making, 24, 4, pp. 361-376.

Ding, M., Grewal, R. and Liechty, J. (2005) 'Incentive-aligned conjoint analysis', Journal of Marketing Research, pp. 67-82.

Dovidio, J.F., Allen, J.L. and Schroeder, D.A. (1990) 'Specificity of empathy-induced helping: Evidence for altruistic motivation', Journal of Personality and Social Psychology, 59, 2, pp. 249-260.

Fisher, Robert J., Mark Vandenbosch, and Kersi D. Antia (2008) 'An empathy-helping perspective on consumers' responses to fund-raising appeals', Journal of Consumer Research, 35, 3, pp. 519-531.

Fultz, J., Schaller, M. and Cialdini, R.B. (1988) 'Empathy, sadness, and distress three related but distinct vicarious affective responses to another's suffering', Personality and Social Psychology Bulletin, 14, 2, pp. 312-325.

Gaertner, S. L. and Dovidio, J. F. (1977) 'The subtlety of white racism, arousal, and helping behavior', Journal of Personality and Social Psychology, 35, 10, pp. 691-707.

Goffrnan, E. (1959) The presentation of self in everyday life. New York: Doubleday Anchor.

Hollander, H. (1990) 'A social exchange approach to voluntary cooperation', The American Economic Review, pp. 1157-1167. 
Kogut, T. and Ritov, I. (2005) 'The “identified victim” effect: An identified group, or just a single individual?', Journal of Behavioral Decision Making, 18, 3, pp. 157-167.

Krebs, D. (1975) 'Empathy and altruism', Journal of Personality and Social psychology, 32, 6, pp. 1134-1146.

Lang, A. (2000) 'The limited capacity model of mediated message processing', Journal of Communication, 50, 1, pp. $46-70$.

Lang, A. (2006a) 'Motivated cognition (lc4mp): The influence of appetitive and aversive activation on the processing of video games', Digital media: Transformation in human communication, pp. 237-256.

Lang, A. (2006b) 'Using the limited capacity model of motivated mediated message processing to design effective cancer communication messages', Journal of Communication, 56, s1, pp. S57-S80.

Leary, M.R. and Kowalski, R.M. (1990) 'Impression management: A literature review and two-component model', Psychological bulletin, 107, 1, p. 34.

Loewenstein, G. and Small, D.A. (2007) 'The scarecrow and the tin man: The vicissitudes of human sympathy and caring', Review of General Psychology, 11, 2, pp. 112-126.

Martin, M.W. (1994) Virtuous giving: Philanthropy, voluntary service, and caring, Indiana University Press.

Metcalfe, J. and Mischel, W. (1999) 'A hot/cool-system analysis of delay of gratification: dynamics of willpower', Psychological review, 106, 1, pp. 3-19.

Piliavin, J.A., Dovidio, J.F., Gaertner, S.L. and Clark III, R.D. (1981) Emergency intervention. New York: Academic Press.

Reed, A., Aquino, K. and Levy, E. (2007) 'Moral identity and judgments of charitable behaviors', Journal of Marketing, pp. 178-193.

Rossi, P.E., Allenby, G.M. and McCulloch, R. (2005) Bayesian Statistics and Marketing, John Wiley and Sons Ltd.

Sieg, H. and Zhang, J. (2012) 'The effectiveness of private benefits in fundraising of local charities', International Economic Review, 53, 2, pp. 349-374.

Silverman, W.K., Robertson, S.J., Middlebrook, J.L. and Drabman, R.S. (1984) 'An investigation of pledging behavior to a national charitable telethon', Behavior Therapy, 15, 3, pp. 304-311.

Small, D.A. and Loewenstein, G. (2003) 'Helping a victim or helping the victim: Altruism and identifiability', Journal of Risk and Uncertainty, 26, 1, pp. 5-16.

Small, D.A., Loewenstein, G. and Slovic, P. (2007) 'Sympathy and callousness: The impact of deliberative thought on donations to identifiable and statistical victims', Organizational Behavior and Human Decision Processes, 102, 2, pp. 143-153.

Small, D. A. and Simonsohn, U. (2008) 'Friends of victims: Personal experience and prosocial behavior', Journal of Consumer Research, 35, 3, pp. 532-542.

Small, D.A. and Verrochi, N.M. (2009) 'The face of need: Facial emotion expression on charity advertisements', Journal of Marketing Research, 46, 6, pp. 777-787.

Smith, K.D., Keating, J.P. and Stotland, E. (1989) 'Altruism reconsidered: The effect of denying feedback on a victim's status to empathic witnesses', Journal of Personality and Social Psychology, 57, 4, pp. 641-650.

White, K. and Peloza, J. (2009) 'Self-benefit versus other-benefit marketing appeals: Their effectiveness in generating charitable support', Journal of Marketing, 73, 4, pp. 109-124. 